\title{
Alteration and dysfunction of ion channels/transporters in a hypoxic microenvironment results in the development and progression of gastric cancer
}

\author{
Junling Chen ${ }^{1,2} \cdot$ Minglin Zhang ${ }^{1,2} \cdot$ Zhiyuan $\mathrm{Ma}^{1,2,3} \cdot$ Dumin Yuan ${ }^{1,2} \cdot$ Jiaxing Zhu ${ }^{1,2} \cdot$ Biguang Tuo $^{1,2} \cdot{\text { Taolang } \mathrm{Li}^{3}}^{3}$ \\ Xuemei Liu ${ }^{1,2}$ (i)
}

Accepted: 19 March 2021 / Published online: 15 April 2021

(C) The Author(s) 2021

\begin{abstract}
Background Gastric cancer (GC) is one of the most common malignant cancers in the world and has only few treatment options and, concomitantly, a poor prognosis. It is generally accepted now that the tumor microenvironment, particularly that under hypoxia, plays an important role in cancer development. Hypoxia can regulate the energy metabolism and malignancy of tumor cells by inducing or altering various important factors, such as oxidative stress, reactive oxygen species (ROS), hypoxiainducible factors (HIFs), autophagy and acidosis. In addition, altered expression and/or dysfunction of ion channels/ transporters (ICTs) have been encountered in a variety of human tumors, including GC, and to play an important role in the processes of tumor cell proliferation, migration, invasion and apoptosis. Increasing evidence indicates that ICTs are at least partly involved in interactions between cancer cells and their hypoxic microenvironment. Here, we provide an overview of the different ICTs that regulate or are regulated by hypoxia in GC.

Conclusions and perspectives Hypoxia is one of the major obstacles to cancer therapy. Regulating cellular responses and factors under hypoxia can inhibit GC. Similarly, altering the expression or activity of ICTs, such as the application of ion channel inhibitors, can slow down the growth and/or migration of GC cells. Since targeting the hypoxic microenvironment and/or ICTs may be a promising strategy for the treatment of GC, more attention should be paid to the interplay between ICTs and the development and progression of GC in such a microenvironment.
\end{abstract}

Keywords Gastric cancer $\cdot$ Ion channel $\cdot$ Tumor microenvironment $\cdot$ Hypoxia $\cdot$ ROS $\cdot$ HIF

\section{Introduction}

Gastric cancer (GC) is the fifth most common malignancy and the third most common cause of cancer-related death

Xuemei Liu and Taolang Li contributed equally and share corresponding authorship.

Taolang Li

0078029@sina.com

Xuemei Liu

onlyoneliuxuemei@163.com

1 Department of Gastroenterology, Affiliated Hospital of Zunyi Medical University, Zunyi 563003, Guizhou Province, China

2 Digestive Disease Institute of Guizhou Province, Zunyi, Guizhou Province, China

3 Department of Thyroid and Breast Surgery, Affiliated Hospital of Zunyi Medical University, Zunyi 563003, Guizhou Province, China worldwide [1]. Due to the poor prognosis of GC, its related five-year survival rate does not exceed $30 \%$ in most countries $[2,3]$. Therefore, intensive research on the pathogenesis of $\mathrm{GC}$ and the development of novel and effective drugs and treatment options are essential.

Recent studies have shown that cancer progression and metastasis depend on bidirectional interactions between cancer cells and their environment, which together form the tumor microenvironment (TME) [4]. The TME is a complex, dynamic network composed of cellular and noncellular components $[5,6]$ that is characterized by hypoxia, an acidic extracellular $\mathrm{pH}(\mathrm{pHe})$, high lactate levels, strongly elevated adenosine concentrations, low levels of glucose, ATP and nutrients and the presence of VEGF and many other cytokines and growth factors [7-9]. Among these factors, hypoxia is of particular concern. Solid tumors generally contain hypoxic regions that can trigger important cellular changes [10]. Moreover, cancer cells metabolize glucose in the form of 
glycolysis ('Warburg effect'), and hypoxia can further aggravate the dependence on glycolytic fueling, which results in the production of large amounts of lactic acid [11, 12]. However, cancer cells maintain an intracellular $\mathrm{pH}(\mathrm{pHi})$ equal to or higher than that of normal cells, which indicates that these cells can increase the net acid excretion level [13-16]. This can be achieved by upregulating the expression and/or activity of acid excretion carriers and/or by downregulating the expression and/or activity of acid addition carriers. Therefore, the role of ion channels and transporters (ICTs) has become a focus of cancer research (Fig. 1).

ICTs are a class of membrane proteins [17] that are closely related to almost every biological process in the human body, such as cell proliferation, apoptosis, migration, volume regulation, epithelial secretion, contraction and regulation of smooth muscle cells, and regulation of the $\mathrm{pH}$ balance and cell cycle [18-22]. Moreover, increasing evidence indicates that ICTs may be involved in interactions between cancer cells and the TME. Recent studies have shown that hypoxia can simultaneously increase transient receptor almelastatin-like7 channel (TRPM7) expression and induce HIF- $1 \alpha$ accumulation in androgen-independent prostate cancer cells. TRPM7 silencing, however, significantly promoted hypoxia-inducible factor 1 alpha (HIF-1 $\alpha$ ) degradation through the proteasome and inhibited EMT changes in androgen-independent prostate cancer cells under hypoxic conditions [23]. Numerous studies have shown that HIF-1 $\alpha$ acts as a main transcription factor that mediates hypoxic responses and promotes the transcription of angiogenic factors such as VEGF, which leads to an increase in glycolysis through the inhibition of mitochondrial oxidative phosphorylation [24]. In contrast, HIF-1 $\alpha$ stability may depend on high levels of reactive oxygen species (ROS) in hypoxic cancer cells $[25,26]$, which can activate the NF- $k B, T N F-\alpha$ and STAT3 signaling pathways in inflammatory cells and tumor cells to release a variety of inflammatory cytokines involved in changes in the TME [27]. Recent studies have found that HIF- $1 \alpha$ promotes the proliferation, migration, invasion, angiogenesis and endothelial-mesenchymal transition (EMT) of GC cells [28]. The levels of ROS have been found to be significantly increased in patients with GC, and abnormally high levels of ROS to induce oxidative stress, which can damage the gastric mucosa and be an important factor in the development of GC [29]. In addition, hypoxia can induce autophagy and an acidic extracellular $\mathrm{pH}$ through intermediate components or modes, which are also associated with GC progression and chemoresistance [30-34].

In this context, deciphering the crosstalk between ICTs and various components in the TME during hypoxic responses of GC cells deserves special attention. Previously, the physiological and pathophysiological significance of gastric ICTs in GC have been summarized [35]. Here, we review the ICTs that are regulated by hypoxia or regulate the response to hypoxia in $\mathrm{GC}$, including aquaporin 3 (AQP3), chloride intracellular channel 1 (CLIC1), hERG potassium channel, acid-sensing

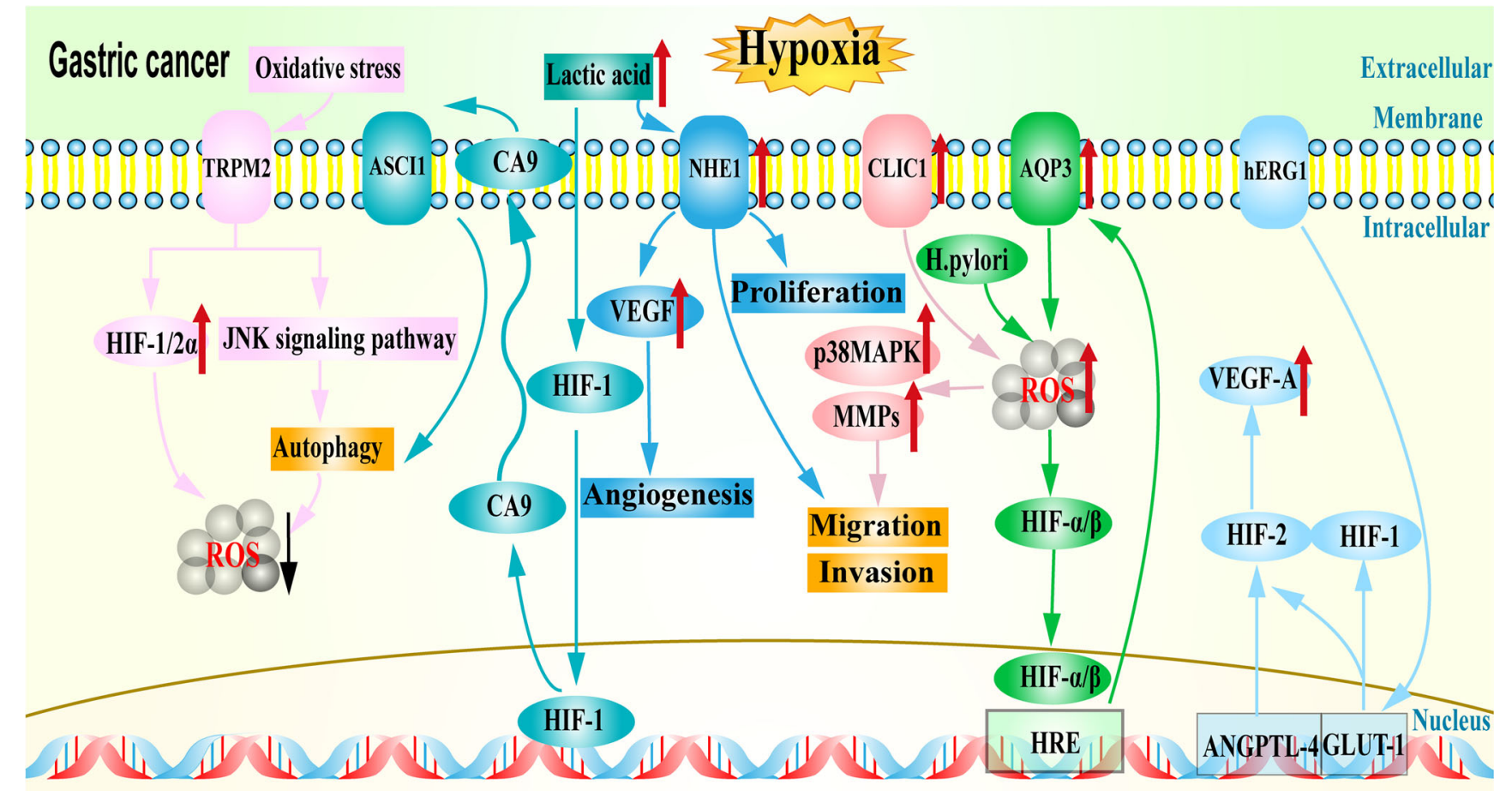

Fig. 1 Diagram of ICTs in the hypoxic microenvironment regulating the development of GC. Different ICTs are shown in different colors; red arrows indicate upregulation and black arrow indicates downregulation 
ion channel 1 (ASIC1), $\mathrm{Na}^{+} / \mathrm{H}^{+}$exchanger1 (NHE1) and transient receptor potential melastatin 2 (TRPM2), which have not been discussed in detail before.

\section{2 lon channels regulate the response to hypoxia}

\subsection{AQP3 participates in the development of GC through the ROS-HIF-1a-AQP3-ROS loop}

Aquaporins (AQPs) are members of a specialized superfamily of membrane integral proteins [36] that includes 13 different aquaporin (AQP0-AQP12) isoforms, which are widespread among microorganisms, plants and mammals [37, 38]. Structurally, each $\sim 30-\mathrm{kDa}$ AQP monomer consists of six transmembrane helical domains (H1 - H6) and two short helical segments (HB and HE). Four AQP monomers aggregate on the plasma membrane to form a tetramer $[39,40]$. AQPs form the main transcellular route of water transport in the gastrointestinal tract and are essential for maintaining body water homeostasis and ensuring digestive and absorptive functions. Currently, at least 10 aquaporins (including AQP1-5 and AQP7-11) have been found to be expressed in the human stomach. Among these AQPs, AQP3, AQP4 and AQP5 present differential expression levels between GCs and corresponding normal tissues [41, 42]. Among the AQPs that have been investigated in GCs, AQP3 is the best studied and subject of this review. AQP3 localizes to the basal layers of epithelial cells and is a major player in barrier hydration and water and osmolyte homeostasis in the human body [43, 44].

A previous study showed that AQP3 is expressed in goblet cells and is positively correlated with gastric intestinal metaplasia (GIM) severity [45]. In addition, it has been found that AQP3 is highly expressed in GC tissues and regulates the proliferation, migration and invasion of human GC cells through a variety of signaling pathways [42]. The PI3K/ AKT signaling pathway is, for example, involved in AQP3mediated transport of glycerol, which can lead to the proliferation of GC cells [46]. A recent study revealed crosstalk between AQP3 and several components involved in the hypoxia response in $H$. pylori-infected gastric mucosa. Several studies have shown that $H$. pylori remains the most common bacterium under these conditions and that infection with this bacterium can lead to chronic gastritis and an increased risk of GC [47]. HIF- $1 \alpha$ activation through persistent hypoxia is closely related to the invasive tumor phenotype and an unfavorable prognosis in patients with GC. In the gastric mucosa of H. pylori infected patients, high levels of ROS are produced by $H$. pylori itself or NADPH, and increased accumulation of intracellular ROS stabilizes HIF- $1 \alpha$ bound to HIF- $1 \beta$ and increases the expression of HIF- $1 \alpha$ in gastric epithelial cells. HIF- $1 \alpha$ is a well-known inducer of VEGF, and the ROS-HIF-
$1 \alpha$ axis plays an important role in the production of VEGF in H. pylori infected gastric epithelial cells [48, 49]. The HIF-1 complex can activate the transcription of many target genes under hypoxic conditions, which results in adaptation to the hypoxic environment. It has been shown that the heterodimeric HIF complex can bind to HREs in the AQP3 promoter region and thereby activate the transcription and upregulation of AQP3. Increased AQP3 levels can mediate ROS uptake and accelerate the accumulation of ROS, and the ROS-HIF$1 \alpha$-AQP3-ROS loop can further upregulate the expression of AQP3. Hypoxia is a characteristic of tumors and in the presence of persistent hypoxia, the ROS-HIF-1-AQP3-ROS loop may continue to operate, even in the absence of $H$. pylori [48]. Another study showed that AQP3 increases autophagy in GC cells and promotes the resistance of GC cells to cisplatin through autophagy, which suggests that AQP3-based therapy may be employed in future GC treatment strategies [50]. In summary, it has been found that AQP3 may be involved in the development of GC, and that crosstalk between $\mathrm{AQP} 3$ and the hypoxia response may be one of the underlying mechanisms.

\subsection{CLIC1 participates in the metastasis and invasion of GC cells by regulating hypoxia-reoxygenation- induced intracellular ROS}

Jentsch and co-workers showed that chloride channels can be divided into six categories: (1) voltage-gated $\mathrm{Cl}^{-}$channels (ClCs), (2) cystic fibrosis transmembrane conductance regulator (CFTR), a cAMP-activated $\mathrm{Cl}^{-}$channel, (3) volumesensitive osmolyte and anion channels (VSOACs), also referred to as swelling-activated $\mathrm{Cl}^{-}$channels, (4) $\mathrm{Ca}^{2+}$-activated $\mathrm{Cl}^{-}$channels (CACCs), (5) p64-related chloride intracellular channels (CLICs) and (6) $\gamma$-aminobutyric acid and glycine receptors, which represent ligand-gated $\mathrm{Cl}^{-}$channels [51]. Among these channels, the CLIC family of proteins consists of seven different members: CLIC1, CLIC2, CLIC3, CLIC4, CLIC5, p64 and parchorin [52]. Following the successful isolation of the p64 protein and the subsequent cloning of its gene, the first human paralogue, NCC27 (later renamed CLIC1), was cloned from the myelomonocytic cell line U937. CLIC1 is located on human chromosome 6p21.3 and encodes a protein of 241 amino acids that is expressed in the nucleus, cytoplasm and cell membrane [53-55]. Ulmasov et al. found that CLIC1 is expressed in the apical domains of several types of simple columnar epithelia, including those of the glandular stomach, small intestine, colon, bile ducts, pancreatic ducts, airways, tail of the epididymis and renal proximal tubules [56]. Chen et al. also found a trace of CLIC1 expression in normal gastric tissue [57]. In addition, it was found that CLIC1 may physiologically participate in changes in cell volume, membrane potential regulation, acidification of intracellular organelles, proliferation and differentiation of cells and cell cycle progression [58]. 
Increasing evidence indicates that CLIC1 is associated with a variety of malignancies, including pleomorphic human sarcoma [59], glioblastoma [60], ovarian cancer [61-63], liver cancer [64], pancreatic cancer [65], gastric cancer [57, 66, 67] and colorectal cancer $[53,68,69]$. CLIC1 is highly expressed in GC and is strongly correlated with lymphatic invasion, lymph node metastasis, perineural invasion and pathological stage. In addition, it has been found that high CLIC1 expression may inhibit the proliferation of GC cells and promote their apoptosis, migration and invasion [57, 67]. It has been shown that CLIC1 acts as a sensor and effector during oxidative stress [70] and affects the progression of various tumors through ROS regulation [69-73]. Previous studies have also shown that hypoxia-reoxygenation (H-R) may increase intracellular ROS levels to activate the MAPK/ERK pathway and that the CLIC1 protein participates in the migration of LOVO colon cancer cells by regulating the ROS/ERK pathway during H-R [69]. Similar to its role in colon cancer, CLIC1 is involved in the migration and invasion of GC cells by regulating intracellular ROS production. At has amply been shown that ROS might act not only to impair cellular and protein function, but also as second messengers in cellular processes involving changes in cellular redox status, such as migration, differentiation and replication. Cellular oxidation can activate kinases such as mitogen-activated protein kinase (MAPK), protein kinase $\mathrm{C}(\mathrm{PKC})$ and protein kinase $\mathrm{B}(\mathrm{PKB})$, and it has been found that changes in cellular redox status are characteristic of some pathological conditions, particularly chronic inflammatory conditions, tumor states and degenerative processes [70]. Under H-R conditions, the level of ROS in SGC7901 GC cells was found to be increased, and the expression of p-p38, MMP-2 and MMP-9 to be significantly increased. These processes are regulated by MAPK signal transduction pathways [71, 74, 75]. Functional inhibition of CLIC1 downregulates $\mathrm{H}-\mathrm{R}$-induced intracellular ROS production in GC cells, and the p38 MAPK inhibitor Sb203580 inhibits HR-induced GC cell motility. These results suggest that CLIC1 may regulate the migration and invasion of GC cells through the ROS-mediated p38 MAPK signaling pathway [71]. In conclusion, a clear correlation between CLIC1 expression and the migration and invasion of GC cells has been observed, and the subsequent finding that CLIC1 regulates the response to hypoxia during the development of GC contributes to our understanding of the mechanism underlying $\mathrm{GC}$ cell invasion and metastasis.

\section{3 hERG1 channels induce GC and regulate VEGF-A secretion via HIFs}

Potassium channels represent the largest group of ion channels in the human genome. Based on similarities in amino acid sequences and functional properties, the genes encoding pore-forming subunits can be subdivided into three major families: (1) channel subunits with six or seven transmembrane domains and one pore loop (6/7TM-1P), which are known as voltage-gated and $\mathrm{Ca}^{2+}$-activated $\mathrm{K}^{+}$channels, (2) channel subunits with four transmembrane domains and two pore loops (4TM-2P), which are known as K2P channels and (3) channel subunits with two transmembrane domains and one pore loop (2TM-1P), which are considered inward rectifying $\mathrm{K}^{+}$channels [76]. Potassium channels are located on the outer cell membrane and participate in fundamental processes such as cell membrane excitability, ion and solute transport and cell volume regulation. Potassium channels are physiologically involved in maintaining the external $\mathrm{K}^{+}$balance in epithelial cells of the gastrointestinal system and play an important role in the production of gastric acid and the secretion of gastric juice $[77,78]$. The ether-a-go-go (EAG) potassium channel family, which encompasses alpha subunits of sixtransmembrane-domain voltage-gated $\mathrm{K}^{+}$(VGK) channels, has been divided into three subfamilies: EAG, EAG-related gene (ERG) and EAG-like (ELK) $\mathrm{K}^{+}$channels [79]. The human EAG-related gene (HERG) was cloned using a human hippocampal cDNA library, is located at chromosome 7q3536, and encodes 1159 amino acids [80]. hERG potassium channels are normally expressed in heart, vascular smooth muscle, brain, thymus and adrenal gland, but not in the normal gastric mucosal epithelium [81, 82].

Up till now, research on hERG channels has focused on the role of this potassium channel in cardiac repolarization and long QT syndrome (LQTS) [82]. However, these channels have also been found to be overexpressed in a wide range of human cancers [83-85], and it has been reported that the activity of hERG affects three major functions related to tumor cell biology: proliferation, invasion and tumor angiogenesis [86]. hERG mRNA and protein are expressed specifically in GC cells, and the hERG protein localizes to the cytoplasm and membrane of GC cells [87]. hERG1 expression is related to the Lauren intestinal type GC, its fundus localization, grading, TNM stage, lymph node involvement, serosal and venous invasion and VEGF-A expression [86-88]. It has been shown that hERG1 channels are strongly regulated by hypoxia [89]. Under hypoxic conditions, the accumulation of HIF-1 directly upregulates VEGF expression and cooperates with a variety of other factors participating in angiogenesis [90]. Similar to findings in colorectal cancer, hERG1 channels regulate VEGF-A secretion in GC through Akt-dependent regulation of HIF (mainly HIF-2) transcriptional activity. In contrast, hERG1 inhibition decreases the expression of HIF- $1 \alpha$ and HIF- $2 \alpha$-coregulated (GLUT-1) and HIF- $2 \alpha$-regulated (ANGPTL-4) genes without affecting the expression of the LDHA gene. Additionally, it has been found that a hERG1 inhibitor can decrease Akt activity, and that PI3K/AKT inhibitor treatment can inhibit HIF-1 activity and significantly decrease VEGF-A secretion. Notably, hERG1 is expressed early during GC progression and may, therefore, be of value in 
predicting the prognosis, clinical course and/or response to chemotherapy in patients with GC $[86,88]$. Considering that hERG1 is closely related to hypoxia and that HIFs remain promising anti-angiogenic agents and direct targets for interfering with the energetics of cancer cells to regulate their growth [91], the possibility of combining hERG channel blockers with drugs targeting hypoxia-related components or developing analogous schemes should be considered in future studies.

\section{Hypoxia affects the expression and function of ICTs in GC}

\subsection{Hypoxia promotes the opening of ASIC1 channels, which regulate $\mathrm{GC}$ through autophagy}

Acid-sensitive ion channels (ASICs), also known as $\mathrm{H}^{+}$-gated cation channels, are a class of ligand-gated cation channels belonging to the mechanosensitive epithelial $\mathrm{Na}^{+}$channel/ degenerin (ENaC/DEG) superfamily. ASICs are sensitive to amiloride and independent of voltage [92-94]. To date, five mammalian genes (Accn1-5) encoding seven ASIC subtypes (ASCI1a, ASIC1b, ASIC2a, ASIC2b, ASIC3, ASIC4 and ASIC5) have been cloned [95]. ASICs occur as trimers [96], and each ASIC subunit is composed of approximately 500 amino acids and consists of two hydrophobic transmembrane domains, i.e., transmembrane domain 1 (TMD1) and transmembrane domain 2 (TMD2), a large cysteine-rich extracellular loop and an intracellular domain containing the carboxyl (C) and amino $(\mathrm{N})$ ends [97]. ASICs are almost ubiquitously expressed in the mammalian nervous system in both peripheral and central nerves, are involved in neurosensory mechano-transduction in multiple tissues and organs, and have been implicated in touch, pain, digestive function, baroreceptors, blood volume control and hearing [95, 97]. There is ample evidence indicating that ASICs play an important role in mucosal homeostasis of the upper gastrointestinal tract (stomach, esophagus and duodenum). To avoid tissue damage, the secretion of gastric acid must be strictly controlled according to the body's needs, and acid-sensitive protective mechanisms must be present in all parts of the intestine that may be exposed to excessive lumen acid [98]. Currently, there is much scientific evidence supporting the notion that ASICs are expressed in a variety of cancers, play a role in the acidic microenvironment by regulating multiple malignant processes in tumors, including proliferation, invasion and migration, and can affect cell cycle progression [99-106].

It has been shown that cancer is a malignant disease characterized by microenvironmental hypoxia due to abnormal blood vessels and a poor blood flow. Under hypoxia, cells convert aerobic respiration into glycolysis, which results in the intracellular or extracellular accumulation of lactate and acidification of the extracellular environment. If the extracellular environment is acidified, HIF-1 is activated and binds to DNA to promote the expression of carbonic anhydrase 9 (CA9). CA9 on the cell membrane can alleviate intracellular acidosis via anion exchangers, which results in reduction in extracellular $\mathrm{pH}$ and the opening of ASICs [107]. ASIC1 participates in acidosis-mediated signal transduction through calcium influx, which is one of the mechanisms through which a low extracellular $\mathrm{pH}$ in the microenvironment promotes the growth and metastasis of tumors [100,108-111]. To date, few studies have investigated the involvement of ASICs in the occurrence and development of GC. Zhang Q et al. found that autophagy plays an important role in the regulation of GC cell growth by ASIC1. Previous studies have shown that the acidic tumor microenvironment can induce the expression of autophagy-related genes and promote autophagy, and that autophagy represents the lysosomal catabolism pathway of proteins and organelles. It has also been reported that the RNA and protein expression levels of autophagy-related 5 (ATG5) and ASIC1 are increased in GC tissues. ASIC1 regulates autophagy through ATG5 activation. In a murine GC xenograft model, ASIC1 or ATG5 gene knockdown inhibited the growth of the tumor cells, whereas ASIC1 shRNA treatment led to decreased tumor volumes and prolonged survival times of the animals. Therefore, it was concluded that downregulation of ASIC1 inhibits the growth of GC by reducing autophagy [112]. Subsequent studies have shown that the expression of ASIC1 exhibits a significant correlation with an increased risk of $\mathrm{GC}$ as well as with $\mathrm{GC}$ cell migration and invasion $[113,114]$. Thus, hypoxia causes acidification of the extracellular environment, which in turn promotes the opening of the ASIC1 channel and ultimately regulates GC through autophagy. ASIC1 inhibitors may be used as potential therapeutic drugs.

\subsection{Hypoxia can activate and upregulate NHE1, which is involved in the proliferation, migration and invasion of GC cells}

Human $\mathrm{Na}^{+} / \mathrm{H}^{+}$exchangers (NHEs) are encoded by the SLC9 gene family classified by solute carriers of transporters, including SLC9A1-9 (NHE1-9), SLC9B1-2 (NHA1, NHA2) and SLC9C1-2. Among them, the human NHE1 protein is encoded by SLC9A1 and contains a hydrophobic N-terminal membrane domain responsible for the transport of NHEs and a hydrophilic, intracellular long C-terminus necessary for NHE1 regulation [115]. NHE1 controls cell volume and $\mathrm{pH}$, but is also involved in complex biological processes such as cell adhesion, migration, proliferation and mechano-sensation [116]. NHE1 is strongly expressed in the gastric mucosa and is one of the predominant isoforms in mucous cells that regulate the $\mathrm{pHi}$, particularly in the presence of high gastric acid levels, which is important for gastric barrier action to acids 
and for maintaining a near-neutral $\mathrm{pHi}$ in the gastric mucosa [117]. In addition, NHE1 may be responsible for the initiation of gastric epithelial restitution [118], but is not essential for gastric epithelial repair $[119,120]$. Interestingly, NHE1 has also been found to be involved in insulin-like growth factor IIinduced proliferation and carbachol-/insulin-like growth factor II-stimulated migration of human gastric myofibroblasts [121].

Hypoxia promotes the upregulation of glycolysis to maintain ATP production, which leads to acidosis and thereby promotes the upregulation of NHEs. To date, several studies have shown that in solid tumors NHE1, as the most important cellular $\mathrm{pH}$ regulator, is upregulated, which can be regarded as an adaptive response of cancer cells to hypoxia and acidosis, and that the resulting intracellular alkalinization and extracellular acidification play crucial roles in cancer cell proliferation, invasion and metastasis $[122,123]$. To date, various GC cell models have been established to illustrate the influence of NHE1 on the occurrence and development of GC. In a study on GC SGC-7901 cells, antisense NHE1-transfected SGC7901 cells were found to exhibit proliferation inhibition, G1/ G0 phase arrest, an increased apoptotic rate, recovery of contact inhibition and density contacts, a decreased invasive capacity, a decreased cloning efficiency in soft agar and in vivo tumorigenicity in nude mice [124]. In addition, EIPA (an inhibitor of NHE1) was found to suppress the proliferation of human GC MKN28 cells by upregulating p21 expression through the reduction of cytosolic $\mathrm{Cl}^{-}$[125]. Furthermore, in human GC MKN45 and MKN74 cells, 2-aminophenoxazine3-one (Phx-3) rapidly decreased the pHi by inhibiting NHE1, which resulted in apoptosis [126]. Notably, in human GC SGC7901 cells, NHE1 blockade decreased the pHi values, and this effect was accompanied by a significant decrease in vascular endothelial growth factor (VEGF) mRNA and protein expression [127]. The available evidence clearly shows that VEGF overexpression is critical to tumor formation and angiogenesis. Overall, the above results suggest that NHE1 exerts a strong effect on the occurrence and malignant biological behavior of GC cells. Therefore, regulating the expression and activity of NHE1 through intervention of the response to hypoxia may effectively hamper the development of GC.

\subsection{Hypoxia promotes the opening of TRPM2 channels and induces GC through autophagy}

The transient receptor potential (TRP) channel superfamily belongs to the voltage-gated ion channel superfamily, which includes voltage-gated $\mathrm{K}^{+}, \mathrm{Na}^{+}$and $\mathrm{Ca}^{2+}$ channels and related cyclic nucleotide-gated channels. These proteins form tetramers of the same subunit [128]. The proteins forming the 28 known mammalian TRP channels can be divided into six subfamilies based on amino acid sequence homology (TRPC, TRPV, TRPM, TRPA, TRPP and TRPML) [128, 129]. In many ways, the TRPM (transient receptor potential melastatin) subfamily is the largest and most diverse subfamily of TRP channels [130]. TRPM2, one of the eight members of the TRPM subfamily, is a $\mathrm{Ca}^{2+}$-permeable cation channel. TheTRPM2 gene is located on human chromosome 21q22.3 and consists of 32 exons encoding a protein of 1503 amino acids with a predicted molecular mass of $\sim 170 \mathrm{kDa}[131$, 132]. TRPM 2 is mainly expressed in the central nervous system, immune cells and pancreatic cells [133] and plays a key role in immune responses [134-136], insulin secretion [137], oxidative stress [138] and body temperature control [139, 140]. In many physiological processes, TRPM2 plays a protective role. In cardiomyocytes, sustained $\mathrm{Ca}^{2+}$ entry through TRPM2 reduces ROS and maintains better mitochondrial bioenergetics, which protects the heart from oxidative damage after H-R [141].

A growing body of evidence indicates that TRPM2 is highly expressed in various cancers and protects the viability of many cell types after oxidative stress [142, 143]. Hypoxia can cause oxidative stress, and ADP-ribose (ADPR) produced after oxidative stress activates TRPM2 and binds to its C-terminus, which causes the channel to open. Activation of TRPM2 leads to the expression of a variety of transcription factors and kinases that are important in cell proliferation and survival, including HIF-1/2 $\alpha$, CREB, nuclear factor (erythroid-derived 2)-related factor-2 (Nrf2), Pyk2 and Src phosphorylation. Inhibition of the TRPM2-mediated calcium influx is associated with increased ROS production, impairments in autophagy and DNA repair, defective mitochondrial metabolism, reduced cellular bioenergetics, decreased tumor growth and increased sensitivity to chemotherapy [143]. To date, only few studies have investigated the role of TRPM2 in GC. In 2018 Almasi et al. provided the first evidence that TRPM2 is functionally expressed in $\mathrm{GC}$ cells and acts as a plasma membrane ion channel for calcium penetration. The authors found that shRNA-mediated downregulation of TRPM2 in two GC cell lines, AGS and MKN-45, led to a slowdown of the growth of the cells and increased the percentage of apoptotic cells. TRPM2 knockout has been found to downregulate the c-Jun terminal kinase (JNK) signaling pathway, which subsequently impairs autophagy and mitophagy. These impairments led to the accumulation of damaged mitochondria and decreases in basal and maximal mitochondrial oxygen consumption and ATP production, which ultimately caused GC cell death. In addition, the authors found that TRPM2 downregulation sensitized GC cells to paclitaxel and doxorubicin [144], which was consistent with the results of neuroblastoma studies. In a neuroblastoma study, it was found that the expression of HIF$1 / 2 \alpha$ in TRPM2-S-expressing tumor cells was significantly decreased and that the reduction in the survival of TRPM2S-expressing cells could be rescued by functional enhancement of HIF- $1 \alpha$ or HIF- $2 \alpha$. These results confirm that TRPM2 plays an important role in the regulation of ROS 
and HIF levels and tumor cell survival, as well as improvements in cell survival observed after doxorubicin treatment [141]. However, whether HIF exerts an effect on TRPM2 in $\mathrm{GC}$ remains to be investigated. Almasi et al. also found that the TRPM2 expression level is negatively correlated with the survival rate of patients with GC, which suggests that the application of TRPM2 targeting combined with chemotherapeutic drugs may be used as a strategy to improve current therapeutic effects and to improve the prognosis of patients with GC [144]. These researchers also found that TRPM2 promotes the migration, invasion and growth of GC cells through the AKT signaling pathway [145]. Based on the above-described findings, TRPM2 may promote the survival and growth of GC cells by helping them to cope with hypoxiainduced oxidative stress and by regulating hypoxia-induced transcription factor expression, mitochondrial function and mitophagy.

\section{Conclusions and perspectives}

A hypoxic microenvironment is a key hallmark of solid tumors. Alterations and/or dysfunction of ion channels are encountered in almost all cancer types. However, one aspect that has received less attention is that the activity of ICTs is highly sensitive to a hypoxic microenvironment, highlighting a putative important role of ICTs in regulating cancer development in a such a microenvironment. Here, we outline interactive connections between multiple ICTs and various components during the hypoxic response of GC cells. We believe that both the hypoxic microenvironment and ICTs may serve as effective targets for the treatment of GC. Obtaining a better understanding of the relationship between hypoxia and ICTs in the context of GC may pave the way for a more efficacious targeted treatment of GC.

Acknowledgements We thank GRW, HJ and JXA for suggestions and supporting experiments.

Code availability No applicable.

Author's contributions Xuemei Liu and Taolang Li conceived and designed the research; Jiaxing Zhu, Zhiyuan Ma and Dumin Yuan analyzed the data; Junling Chen and Minglin Zhang prepared the figure; Junling Chen drafted the manuscript; Taolang Li and Xuemei Liu edited and revised the manuscript; Biguang Tuo, Taolang Li and Xuemei Liu approved the final version of the manuscript.

Funding This research was supported by the National Natural Science Foundation of China (81860103 and 82070536 to X.M.L. and 81660098 to T.T.L.), the Outstanding Scientific Youth Fund of Guizhou Province (2017-5608 to X.M.L.), the 15851 Talent Projects of Zunyi City (to T.T.L.) and Guizhou Province Science Plan Program (Qian Ke He Foundation-ZK [2021] General 461 to T.T.L.)
Data availability Not applicable.

\section{Declarations}

Ethics approval Not applicable.

Consent to participate Not applicable.

Consent for publication Not applicable.

Conflicts of interest/competing interests The authors declare that they have no competing or conflicting interests.

Open Access This article is licensed under a Creative Commons Attribution 4.0 International License, which permits use, sharing, adaptation, distribution and reproduction in any medium or format, as long as you give appropriate credit to the original author(s) and the source, provide a link to the Creative Commons licence, and indicate if changes were made. The images or other third party material in this article are included in the article's Creative Commons licence, unless indicated otherwise in a credit line to the material. If material is not included in the article's Creative Commons licence and your intended use is not permitted by statutory regulation or exceeds the permitted use, you will need to obtain permission directly from the copyright holder. To view a copy of this licence, visit http://creativecommons.org/licenses/by/4.0/.

\section{References}

1. F. Bray, J. Ferlay, I. Soerjomataram, R.L. Siegel, L.A. Torre, A. Jemal, Global cancer statistics 2018: GLOBOCAN estimates of incidence and mortality worldwide for 36 cancers in 185 countries. CA Cancer J. Clin. 68, 394-424 (2018)

2. D. Hashim, P. Boffetta, C. La Vecchia, M. Rota, P. Bertuccio, M. Malvezzi, E. Negri, The global decrease in cancer mortality: Trends and disparities. Ann. Oncol. 27, 926-933 (2016)

3. C. Allemani, T. Matsuda, V. Di Carlo, R. Harewood, M. Matz, M. Niksic, A. Bonaventure, M. Valkov, C.J. Johnson, J. Esteve, O.J. Ogunbiyi, E.S.G. Azevedo, W.Q. Chen, S. Eser, G. Engholm, C.A. Stiller, A. Monnereau, R.R. Woods, O. Visser, G.H. Lim, J. Aitken, H.K. Weir, M.P. Coleman, Global surveillance of trends in cancer survival 2000-14 (CONCORD-3): analysis of individual records for 37513025 patients diagnosed with one of 18 cancers from 322 population-based registries in 71 countries. Lancet 391, 1023-1075 (2018)

4. O. Meurette, P. Mehlen, Notch signaling in the tumor microenvironment. Cancer Cell 34, 536-548 (2018)

5. D.C. Hinshaw, L.A. Shevde, The tumor microenvironment innately modulates cancer progression. Cancer Res. 79, 4557-4566 (2019)

6. S.C. Casey, A. Amedei, K. Aquilano, A.S. Azmi, F. Benencia, D. Bhakta, A.E. Bilsland, C.S. Boosani, S. Chen, M.R. Ciriolo, S. Crawford, H. Fujii, A.G. Georgakilas, G. Guha, D. Halicka, W.G. Helferich, P. Heneberg, K. Honoki, W.N. Keith, S.P. Kerkar, S.I. Mohammed, E. Niccolai, S. Nowsheen, H.P.V. Rupasinghe, A. Samadi, N. Singh, W.H. Talib, V. Venkateswaran, R.L. Whelan, X. Yang, D.W. Felsher, Cancer prevention and therapy through the modulation of the tumor microenvironment. Semin. Cancer Biol. 35(Suppl), S199-s223 (2015)

7. A.K. Pedersen, J. M. L. de Melo, N. Morup, K. Tritsaris, S.F. Pedersen, Tumor microenvironment conditions alter Akt and $\mathrm{Na}(+) / \mathrm{H}(+)$ exchanger NHE1 expression in endothelial cells more 
than hypoxia alone: implications for endothelial cell function in cancer. BMC Cancer 17, 542 (2017)

8. A.P. Andersen, J.M. Moreira, S.F. Pedersen, Interactions of ion transporters and channels with cancer cell metabolism and the tumour microenvironment. Philos. Trans. R. Soc. Lond. Ser. B Biol. Sci. 369, 20130098 (2014)

9. P. Vaupel, G. Multhoff, Hypoxia-/HIF-1alpha-driven factors of the tumor microenvironment impeding antitumor immune responses and promoting malignant progression. Adv. Exp. Med. Biol. 1072, 171-175 (2018)

10. A. Patel, S. Sant, Hypoxic tumor microenvironment: Opportunities to develop targeted therapies. Biotechnol. Adv. 34, 803-812 (2016)

11. A. Tosatto, R. Sommaggio, C. Kummerow, R.B. Bentham, T.S. Blacker, T. Berecz, M.R. Duchen, A. Rosato, I. Bogeski, G. Szabadkai, R. Rizzuto, C. Mammucari, The mitochondrial calcium uniporter regulates breast cancer progression via HIF-1 $\alpha$. EMBO Mol. Med. 8, 569-585 (2016)

12. M.G. Vander Heiden, L.C. Cantley, C.B. Thompson, Understanding the Warburg effect: The metabolic requirements of cell proliferation. Science 324, 1029-1033 (2009)

13. S.F. Pedersen, C. Stock, Ion channels and transporters in cancer: Pathophysiology, regulation, and clinical potential. Cancer Res. 73, 1658-1661 (2013)

14. S.K. Parks, J. Chiche, J. Pouysségur, Disrupting proton dynamics and energy metabolism for cancer therapy. Nat. Rev. Cancer 13, 611-623 (2013)

15. E. Boedtkjer, L. Bunch, S.F. Pedersen, Physiology, pharmacology and pathophysiology of the $\mathrm{pH}$ regulatory transport proteins NHE1 and NBCn1: Similarities, differences, and implications for cancer therapy. Curr. Pharm. Des. 18, 1345-1371 (2012)

16. B.A. Webb, M. Chimenti, M.P. Jacobson, D.L. Barber, Dysregulated $\mathrm{pH}$ : A perfect storm for cancer progression. Nat. Rev. Cancer 11, 671-677 (2011)

17. E. Lastraioli, J. Iorio, A. Arcangeli, Ion channel expression as promising cancer biomarker. Biochim. Biophys. Acta 1848, 2685-2702 (2015)

18. D.L. Neverisky, G.W. Abbott, Ion channel-transporter interactions. Crit. Rev. Biochem. Mol. Biol. 51, 257-267 (2015)

19. A. Litan, S.A. Langhans, Cancer as a channelopathy: Ion channels and pumps in tumor development and progression. Front. Cell. Neurosci. 9, 86 (2015)

20. A. Kondratskyi, K. Kondratska, R. Skryma, N. Prevarskaya, Ion channels in the regulation of apoptosis. Biochim. Biophys. Acta 1848, 2532-2546 (2015)

21. E.K. Hoffmann, N.B. Holm, I.H. Lambert, Functions of volumesensitive and calcium-activated chloride channels. IUBMB Life 66, 257-267 (2014)

22. D.C. Gadsby, Ion channels versus ion pumps: The principal difference, in principle. Nat. Rev. Mol. Cell Biol. 10, 344-352 (2009)

23. F. Yang, J. Cai, H. Zhan, J. Situ, W. Li, Y. Mao, Y. Luo, Suppression of TRPM7 inhibited hypoxia-induced migration and invasion of androgen-independent prostate cancer cells by enhancing RACK1-mediated degradation of HIF-1 $\alpha$. Oxidative Med. Cell. Longev. 2020, 6724810 (2020)

24. U.E. Martinez-Outschoorn, C. Trimmer, Z. Lin, D. WhitakerMenezes, B. Chiavarina, J. Zhou, C. Wang, S. Pavlides, M.P. Martinez-Cantarin, F. Capozza, A.K. Witkiewicz, N. Flomenberg, A. Howell, R.G. Pestell, J. Caro, M.P. Lisanti, F. Sotgia, Autophagy in cancer associated fibroblasts promotes tumor cell survival: Role of hypoxia, HIF1 induction and NFkappaB activation in the tumor stromal microenvironment. Cell Cycle 9, 3515-3533 (2010)

25. Y. Kitajima, K. Miyazaki, The critical impact of HIF-1a on gastric cancer biology. Cancers (Basel) 5, 15-26 (2013)
26. J.H. Park, T.Y. Kim, H.S. Jong, T.Y. Kim, Y.S. Chun, J.W. Park, C.T. Lee, H.C. Jung, N.K. Kim, Y.J. Bang, Gastric epithelial reactive oxygen species prevent normoxic degradation of hypoxia-inducible factor-1alpha in gastric cancer cells. Clin. Cancer Res. 9, 433-440 (2003)

27. H. Gu, T. Huang, Y. Shen, Y. Liu, F. Zhou, Reactive oxygen species-mediated tumor microenvironment transformation: The mechanism of radioresistant gastric cancer. Oxidative Med. Cell. Longev. 2018, 5801209 (2018)

28. G.L. Semenza, Hypoxia-inducible factors: Mediators of cancer progression and targets for cancer therapy. Trends Pharmacol. Sci. 33, 207-214 (2012)

29. A. Bhattacharyya, R. Chattopadhyay, S. Mitra, S.E. Crowe, Oxidative stress: An essential factor in the pathogenesis of gastrointestinal mucosal diseases. Physiol. Rev. 94, 329-354 (2014)

30. S.C. Lim, K.H. Kee, M.J. Lee, R. Hong, S.I. Han, Extracellular acidity-induced expression of Kallikrein-related peptidases 7 and 8 is involved in increased invasiveness of gastric cancer cells. Oncol. Rep. 43, 1705-1713 (2020)

31. X. Wang, X. Che, Y. Yu, Y. Cheng, M. Bai, Z. Yang, Q. Guo, X. Xie, D. Li, M. Guo, K. Hou, W. Guo, X. Qu, L. Cao, Hypoxiaautophagy axis induces VEGFA by peritoneal mesothelial cells to promote gastric cancer peritoneal metastasis through an integrin $\alpha 5$-fibronectin pathway. J. Exp. Clin. Cancer Res. 39, 221 (2020)

32. S.-C. Lim, H. Hwang, S.I. Han, Ellagic acid inhibits extracellular acidity-induced invasiveness and expression of COX1, COX2, snail, twist 1, and c-Myc in gastric carcinoma cells. Nutrients 11, 3023 (2019)

33. T. Maeda, A. Suzuki, K. Koga, C. Miyamoto, Y. Maehata, S. Ozawa, R.-I. Hata, Y. Nagashima, K. Nabeshima, K. Miyazaki, Y. Kato, TRPM5 mediates acidic extracellular $\mathrm{pH}$ signaling and TRPM5 inhibition reduces spontaneous metastasis in mouse B16BL6 melanoma cells. Oncotarget 8, 78312-78326 (2017)

34. R. Hong, S.I. Han, Extracellular acidity enhances tumor necrosis factor-related apoptosis-inducing ligand (TRAIL)-mediated apoptosis via DR5 in gastric cancer cells. Korean J. Physiol. Pharmacol. 22, 513-523 (2018)

35. D. Yuan, Z. Ma, B. Tuo, T. Li, X. Liu, Physiological significance of ion transporters and channels in the stomach and pathophysiological relevance in gastric cancer. Evid. Based Complement. Alternat. Med. 2020, 2869138 (2020)

36. J. Xia, H. Wang, S. Li, Q. Wu, L. Sun, H. Huang, M. Zeng, Ion channels or aquaporins as novel molecular targets in gastric cancer. Mol. Cancer 16, 54 (2017)

37. J.M. Carbrey, P. Agre, Discovery of the aquaporins and development of the field. Handbook Exp. Pharmacol. 3-28 (2009)

38. F. Magni, C. Sarto, D. Ticozzi, M. Soldi, N. Bosso, P. Mocarelli, M.G. Kienle, Proteomic knowledge of human aquaporins. Proteomics 6, 5637-5649 (2006)

39. B. $\mathrm{Wu}, \mathrm{E}$. Beitz, Aquaporins with selectivity for unconventional permeants. Cell. Mol. Life Sci. 64, 2413-2421 (2007)

40. A.S. Verkman, Aquaporins at a glance. J. Cell Sci. 124, 2107$2112(2011)$

41. C. Zhu, Z. Chen, Z. Jiang, Expression, distribution and role of aquaporin water channels in human and animal stomach and intestines. Int. J. Mol. Sci. 17, 1399 (2016)

42. G.P. Nagaraju, R. Basha, B. Rajitha, O.B. Alese, A. Alam, S. Pattnaik, B. El-Rayes, Aquaporins: Their role in gastrointestinal malignancies. Cancer Lett. 373, 12-18 (2016)

43. A. Mobasheri, S. Wray, D. Marples, Distribution of AQP2 and AQP3 water channels in human tissue microarrays. J. Mol. Histol. 36, 1-14 (2005)

44. T. Matsuzaki, T. Suzuki, H. Koyama, S. Tanaka, K. Takata, Water channel protein AQP3 is present in epithelia exposed to the environment of possible water loss. J. Histochem. Cytochem. 47, 1275-1286 (1999) 
45. H. Zhao, J. Wen, X. Dong, R. He, C. Gao, W. Zhang, Z. Zhang, L. Shen, Identification of AQP3 and CD24 as biomarkers for carcinogenesis of gastric intestinal metaplasia. Oncotarget 8, 6338263391 (2017)

46. Z. Li, B. Li, L. Zhang, L. Chen, G. Sun, Q. Zhang, J. Wang, X. Zhi, L. Wang, Z. Xu, H. Xu, The proliferation impairment induced by AQP3 deficiency is the result of glycerol uptake and metabolism inhibition in gastric cancer cells. Tumour Biol. 37, 91699179 (2016)

47. M. Plummer, S. Franceschi, J. Vignat, D. Forman, C. de Martel, Global burden of gastric cancer attributable to helicobacter pylori. Int. J. Cancer 136, 487-490 (2015)

48. J. Wen, Y. Wang, C. Gao, G. Zhang, Q. You, W. Zhang, Z. Zhang, S. Wang, G. Peng, L. Shen, Helicobacter pylori infection promotes Aquaporin 3 expression via the ROS-HIF-1alphaAQP3-ROS loop in stomach mucosa: a potential novel mechanism for cancer pathogenesis. Oncogene 37, 3549-3561 (2018)

49. M.J. Kang, E.J. Song, B.Y. Kim, D.J. Kim, J.H. Park, Helicobacter pylori induces vascular endothelial growth factor production in gastric epithelial cells through hypoxia-inducible factor-1alpha-dependent pathway. Helicobacter 19, 476-483 (2014)

50. X. Dong, Y. Wang, Y. Zhou, J. Wen, S. Wang, L. Shen, Aquaporin 3 facilitates chemoresistance in gastric cancer cells to cisplatin via autophagy. Cell Death Dis. 2, 16087 (2016)

51. T.J. Jentsch, V. Stein, F. Weinreich, A.A. Zdebik, Molecular structure and physiological function of chloride channels. Physiol. Rev. 82, 503-568 (2002)

52. B.M. Tulk, S. Kapadia, J.C. Edwards, CLIC1 inserts from the aqueous phase into phospholipid membranes, where it functions as an anion channel. Am. J. Phys. Cell Phys. 282, C1103-C1112 (2002)

53. P. Wang, C. Zhang, P. Yu, B. Tang, T. Liu, H. Cui, J. Xu, Regulation of colon cancer cell migration and invasion by CLIC1-mediated RVD. Mol. Cell. Biochem. 365, 313-321 (2012)

54. N.S. Heiss, A. Poustka, Genomic structure of a novel chloride channel gene, CLIC2, in Xq28. Genomics 45, 224-228 (1997)

55. S.M. Valenzuela, D.K. Martin, S.B. Por, J.M. Robbins, K. Warton, M.R. Bootcov, P.R. Schofield, T.J. Campbell, S.N. Breit, Molecular cloning and expression of a chloride ion channel of cell nuclei. J. Biol. Chem. 272, 12575-12582 (1997)

56. B. Ulmasov, J. Bruno, P.G. Woost, J.C. Edwards, Tissue and subcellular distribution of CLIC1. BMC Cell Biol. 8, 8 (2007)

57. C.D. Chen, C.S. Wang, Y.H. Huang, K.Y. Chien, Y. Liang, W.J. Chen, K.H. Lin, Overexpression of CLIC1 in human gastric carcinoma and its clinicopathological significance. Proteomics 7, 155-167 (2007)

58. M. Peretti, M. Angelini, N. Savalli, T. Florio, S.H. Yuspa, M. Mazzanti, Chloride channels in cancer: Focus on chloride intracellular channel 1 and 4 (CLIC1 AND CLIC4) proteins in tumor development and as novel therapeutic targets. Biochim. Biophys. Acta 1848, 2523-2531 (2015)

59. E. Murray, L. Hernychova, M. Scigelova, J. Ho, M. Nekulova, J.R. O'Neill, R. Nenutil, K. Vesely, S.R. Dundas, C. Dhaliwal, H. Henderson, R.L. Hayward, D.M. Salter, B. Vojtesek, T.R. Hupp, Quantitative proteomic profiling of pleomorphic human sarcoma identifies CLIC1 as a dominant pro-oncogenic receptor expressed in diverse sarcoma types. J. Proteome Res. 13, 2543-2559 (2014)

60. M. Setti, N. Savalli, D. Osti, C. Richichi, M. Angelini, P. Brescia, L. Fornasari, M.S. Carro, M. Mazzanti, G. Pelicci, Functional role of CLIC1 ion channel in glioblastoma-derived stem/progenitor cells. J. Natl. Cancer Inst. 105, 1644-1655 (2013)

61. B. Singha, S.L. Harper, A.R. Goldman, B.G. Bitler, K.M. Aird, M.E. Borowsky, M.G. Cadungog, Q. Liu, CLIC1 and CLIC4 complement CA125 as a diagnostic biomarker panel for all subtypes of epithelial ovarian cancer. Sci. Rep. 8, 14725 (2018)

62. H. Qu, Y. Chen, G. Cao, C. Liu, J. Xu, H. Deng, Z. Zhang, Identification and validation of differentially expressed proteins in epithelial ovarian cancers using quantitative proteomics. Oncotarget 7, 83187-83199 (2016)

63. Y. Ye, M. Yin, B. Huang, Y. Wang, X. Li, G. Lou, CLIC1 a novel biomarker of intraperitoneal metastasis in serous epithelial ovarian cancer. Tumour Biol. 36, 4175-4179 (2015)

64. S. Zhang, X.M. Wang, Z.Y. Yin, W.X. Zhao, J.Y. Zhou, B.X. Zhao, P.G. Liu, Chloride intracellular channel 1 is overexpression in hepatic tumor and correlates with a poor prognosis. Apmis 121, 1047-1053 (2013)

65. J. Lu, Q. Dong, B. Zhang, X. Wang, B. Ye, F. Zhang, X. Song, G. Gao, J. Mu, Z. Wang, F. Ma, J. Gu, Chloride intracellular channel 1 (CLIC1) is activated and functions as an oncogene in pancreatic cancer. Med. Oncol. 32, 616 (2015)

66. D.L. Zheng, Q.L. Huang, F. Zhou, Q.J. Huang, J.Y. Lin, X. Lin, PA28beta regulates cell invasion of gastric cancer via modulating the expression of chloride intracellular channel 1. J. Cell. Biochem. 113, 1537-1546 (2012)

67. P.F. Ma, J.Q. Chen, Z. Wang, J.L. Liu, B.P. Li, Function of chloride intracellular channel 1 in gastric cancer cells. World J. Gastroenterol. 18, 3070-3080 (2012)

68. D.T. Petrova, A.R. Asif, V.W. Armstrong, I. Dimova, S. Toshev, N. Yaramov, M. Oellerich, D. Toncheva, Expression of chloride intracellular channel protein 1 (CLIC1) and tumor protein D52 (TPD52) as potential biomarkers for colorectal cancer. Clin. Biochem. 41, 1224-1236 (2008)

69. P. Wang, Y. Zeng, T. Liu, C. Zhang, P.W. Yu, Y.X. Hao, H.X. Luo, G. Liu, Chloride intracellular channel 1 regulates colon cancer cell migration and invasion through ROS/ERK pathway. World J. Gastroenterol. 20, 2071-2078 (2014)

70. S. Averaimo, R.H. Milton, M.R. Duchen, M. Mazzanti, Chloride intracellular channel 1 (CLIC1): Sensor and effector during oxidative stress. FEBS Lett. 584, 2076-2084 (2010)

71. W. Zhao, M. Lu, Q. Zhang, Chloride intracellular channel 1 regulates migration and invasion in gastric cancer by triggering the ROS-mediated p38 MAPK signaling pathway. Mol. Med. Rep. 12, 8041-8047 (2015)

72. M. Peretti, F.M. Raciti, V. Carlini, I. Verduci, Mutual influence of $\mathrm{ROS}, \mathrm{pH}$, and CLIC1 membrane protein in the regulation of G1-S phase progression in human glioblastoma stem cells. Mol. Cancer Ther. 17, 2451-2461 (2018)

73. J.R. Lee, J.Y. Lee, H.J. Kim, M.J. Hahn, J.S. Kang, H. Cho, The inhibition of chloride intracellular channel 1 enhances $\mathrm{Ca}(2+)$ and reactive oxygen species signaling in A549 human lung cancer cells. Exp. Mol. Med. 51, 81 (2019)

74. S.-J. Lee, S.-S. Park, U.-S. Lee, W.-J. Kim, S.-K. Moon, Signaling pathway for TNF-alpha-induced MMP-9 expression: Mediation through p38 MAP kinase, and inhibition by anti-cancer molecule magnolol in human urinary bladder cancer 5637 cells. Int. Immunopharmacol. 8, 13-14 (2008)

75. P.-N. Chen, Y.-S. Hsieh, H.-L. Chiou, S.-C. Chu, Silibinin inhibits cell invasion through inactivation of both PI3K-Akt and MAPK signaling pathways. Chem. Biol. Interact. 156, 2-3 (2005)

76. D. Heitzmann, R. Warth, Physiology and pathophysiology of potassium channels in gastrointestinal epithelia. Physiol. Rev. 88, 1119-1182 (2008)

77. Q. Kuang, P. Purhonen, H. Hebert, Structure of potassium channels. Cell. Mol. Life Sci. 72, 3677-3693 (2015)

78. J. Han, S.H. Lee, G. Giebisch, T. Wang, Potassium channelopathies and gastrointestinal ulceration. Gut Liver 10, 881-889 (2016)

79. L.C. Schlichter, J. Jiang, J. Wang, E.W. Newell, F.W. Tsui, D. Lam, Regulation of hERG and hEAG channels by Src and by 
SHP-1 tyrosine phosphatase via an ITIM region in the cyclic nucleotide binding domain. PLoS One 9, e90024 (2014)

80. J.W. Warmke, B. Ganetzky, A family of potassium channel genes related to eag in Drosophila and mammals. Proc. Natl. Acad. Sci. U. S. A. 91, 3438-3442 (1994)

81. R.S. Wymore, G.A. Gintant, R.T. Wymore, J.E. Dixon, D. McKinnon, I.S. Cohen, Tissue and species distribution of mRNA for the IKr-like K+ channel, erg. Circ. Res. 80, 261-268 (1997)

82. J.I. Vandenberg, M.D. Perry, M.J. Perrin, S.A. Mann, Y. Ke, A.P. Hill, hERG K(+) channels: Structure, function, and clinical significance. Physiol. Rev. 92, 1393-1478 (2012)

83. G.A. Smith, H.W. Tsui, E.W. Newell, X. Jiang, X.P. Zhu, F.W. Tsui, L.C. Schlichter, Functional up-regulation of HERG K+ channels in neoplastic hematopoietic cells. J. Biol. Chem. 277, 18528-18534 (2002)

84. L. Bianchi, B. Wible, A. Arcangeli, M. Taglialatela, F. Morra, P. Castaldo, O. Crociani, B. Rosati, L. Faravelli, M. Olivotto, E. Wanke, Herg encodes a $\mathrm{K}+$ current highly conserved in tumors of different histogenesis: a selective advantage for cancer cells? Cancer Res. 58, 815-822 (1998)

85. E. Lastraioli, T. Lottini, L. Bencini, M. Bernini, A. Arcangeli, hERG1 potassium channels: Novel biomarkers in human solid cancers. Biomed. Res. Int. 2015, 896432 (2015)

86. R. Zhang, P. Tian, Q. Chi, J. Wang, Y. Wang, L. Sun, Y. Liu, S. Tian, Q. Zhang, Human ether-a-go-go-related gene expression is essential for cisplatin to induce apoptosis in human gastric cancer. Oncol. Rep. 27, 433-440 (2012)

87. X.D. Shao, K.C. Wu, Z.M. Hao, L. Hong, J. Zhang, D.M. Fan, The potent inhibitory effects of cisapride, a specific blocker for human ether-a-go-go-related gene (HERG) channel, on gastric cancer cells. Cancer Biol. Ther. 4, 295-301 (2005)

88. O. Crociani, E. Lastraioli, L. Boni, S. Pillozzi, M.R. Romoli, M. D'Amico, M. Stefanini, S. Crescioli, A. Masi, A. Taddei, L. Bencini, M. Bernini, M. Farsi, S. Beghelli, A. Scarpa, L. Messerini, A. Tomezzoli, C. Vindigni, P. Morgagni, L. Saragoni, E. Giommoni, S. Gasperoni, F. Di Costanzo, F. Roviello, G. De Manzoni, P. Bechi, A. Arcangeli, hERG1 channels regulate VEGF-A secretion in human gastric cancer: clinicopathological correlations and therapeutical implications. Clin. Cancer Res. 20, 1502-1512 (2014)

89. L. Fontana, M. D'Amico, O. Crociani, T. Biagiotti, M. Solazzo, B. Rosati, A. Arcangeli, E. Wanke, M. Olivotto, Long-term modulation of HERG channel gating in hypoxia. Biochem. Biophys. Res. Commun. 286, 857-862 (2001)

90. A. Zimna, M. Kurpisz, Hypoxia-inducible factor-1 in physiological and pathophysiological angiogenesis: Applications and therapies. Biomed. Res. Int. 2015, 549412 (2015)

91. T.A. Ajith, Current insights and future perspectives of hypoxiainducible factor-targeted therapy in cancer. J. Basic Clin. Physiol. Pharmacol. 30, 11-18 (2018)

92. C. Liu, L.L. Zhu, S.G. Xu, H.L. Ji, X.M. Li, ENaC/DEG in tumor development and progression. J. Cancer 7, 1888-1891 (2016)

93. P.W. Reeh, M. Kress, Molecular physiology of proton transduction in nociceptors. Curr. Opin. Pharmacol. 1, 45-51 (2001)

94. R. Waldmann, M. Lazdunski, H(+)-gated cation channels: neuronal acid sensors in the NaC/DEG family of ion channels. Cur.r Opin. Neurobiol. 8, 418-424 (1998)

95. C.C. Chen, C.W. Wong, Neurosensory mechanotransduction through acid-sensing ion channels. J. Cell. Mol. Med. 17, 337349 (2013)

96. J. Jasti, H. Furukawa, E.B. Gonzales, E. Gouaux, Structure of acid-sensing ion channel 1 at 1.9 A resolution and low $\mathrm{pH}$. Nature 449, 316-323 (2007)

97. O. Krishtal, The ASICs: Signaling molecules? Modulators? Trends Neurosci. 26, 477-483 (2003)
98. P. Holzer, Acid-sensing ion channels in gastrointestinal function. Neuropharmacology 94, 72-79 (2015)

99. C. Jin, F.L. Yuan, Y.L. Gu, X. Li, M.F. Liu, X.M. Shen, B. Liu, M.Q. Zhu, Over-expression of ASIC1 a promotes proliferation via activation of the beta-catenin/LEF-TCF axis and is associated with disease outcome in liver cancer. Oncotarget 8, 25977-25988 (2017)

100. S. Zhu, H.Y. Zhou, S.C. Deng, S.J. Deng, C. He, X. Li, J.Y. Chen, Y. Jin, Z.L. Hu, F. Wang, C.Y. Wang, G. Zhao, ASIC1 and ASIC3 contribute to acidity-induced EMT of pancreatic cancer through activating $\mathrm{Ca}(2+) / \mathrm{RhoA}$ pathway. Cell Death Dis. 8, e2806 (2017)

101. J.H. Ye, J. Gao, Y.N. Wu, Y.J. Hu, C.P. Zhang, T.L. Xu, Identification of acid-sensing ion channels in adenoid cystic carcinomas. Biochem. Biophys. Res. Commun. 355, 986-992 (2007)

102. Z.H. Zhou, J.W. Song, W. Li, X. Liu, L. Cao, L.M. Wan, Y.X. Tan, S.P. Ji, Y.M. Liang, F. Gong, The acid-sensing ion channel, ASIC2, promotes invasion and metastasis of colorectal cancer under acidosis by activating the calcineurin/NFAT1 axis. J. Exp. Clin. Cancer Res. 36, 130 (2017)

103. Y. Wu, B. Gao, Q.J. Xiong, Y.C. Wang, D.K. Huang, W.N. Wu, Acid-sensing ion channels contribute to the effect of extracellular acidosis on proliferation and migration of A549 cells. Tumour Biol. 39, 1010428317705750 (2017)

104. Y. Tian, P. Bresenitz, A. Reska, L. El Moussaoui, C.P. Beier, S. Grunder, Glioblastoma Cancer Stem Cell Lines Express Functional Acid Sensing Ion Channels ASIC1a And ASIC3. Sci. Rep. 7, 13674 (2017)

105. S.C. Gupta, R. Singh, M. Asters, J. Liu, X. Zhang, M.R. Pabbidi, K. Watabe, Y.Y. Mo, Regulation of breast tumorigenesis through acid sensors. Oncogene 35, 4102-4111 (2016)

106. A.K. Rooj, C.M. McNicholas, R. Bartoszewski, Z. Bebok, D.J. Benos, C.M. Fuller, Glioma-specific cation conductance regulates migration and cell cycle progression. J. Biol. Chem. 287, 40534065 (2012)

107. G. Yingjun, Q. Xun, Acid-sensing ion channels under hypoxia. Channels (Austin) 7, 231-237 (2013)

108. O. Thews, A. Riemann, Tumor $\mathrm{pH}$ and metastasis: A malignant process beyond hypoxia. Cancer Metastasis Rev. 38, 113-129 (2019)

109. X.C. Weng, J.Q. Zheng, J. Li, W.B. Xiao, Underlying mechanism of ASIC1a involved in acidosis-induced cytotoxicity in rat C6 glioma cells. Acta Pharmacol. Sin. 28, 1731-1736 (2007)

110. X. Sun, D. Zhao, Y.L. Li, Y. Sun, X.H. Lei, J.N. Zhang, M.M. Wu, R.Y. Li, Z.F. Zhao, Z.R. Zhang, C.L. Jiang, Regulation of ASIC1 by $\mathrm{Ca} 2+/$ calmodulin-dependent protein kinase II in human glioblastoma multiforme. Oncol. Rep. 30, 2852-2858 (2013)

111. Y. Zhang, T. Zhang, C. Wu, Q. Xia, D. Xu, ASIC1a mediates the drug resistance of human hepatocellular carcinoma via the $\mathrm{Ca}(2+$ )/PI3-kinase/AKT signaling pathway. Lab. Investig. 97, 53-69 (2017)

112. Q. Zhang, S. Wu, J. Zhu, D. Chai, H. Gan, Down-regulation of ASIC1 suppressed gastric cancer via inhibiting autophagy. Gene 608, 79-85 (2017)

113. X. Chen, X. Sun, Z. Wang, X. Zhou, L. Xu, F. Li, X. Zhang, J. Pan, L. Qi, H. Qian, Z. Mao, Involvement of acid-sensing ion channel 1a in gastric carcinoma cell migration and invasion. Acta Biochim. Biophys. Sin .(Shanghai) 50, 440-446 (2018)

114. A. Heydari-Mehrabadi, D.M. Kordi Tamandani, T. Baranzehi, S. Hemati, Analysis of polymorphism and expression profile of ASIC1 and IL-6 genes in patients with gastric cancer. Asian Pac. J. Cancer Prev. 19, 3451-3455 (2018)

115. M. Donowitz, C. Ming Tse, D. Fuster, SLC9/NHE gene family, a plasma membrane and organellar family of $\mathrm{Na}^{+} / \mathrm{H}^{+}$exchangers. Mol. Asp. Med. 34, 236-251 (2013) 
116. A. Simonin, D. Fuster, Nedd4-1 and beta-arrestin-1 are key regulators of $\mathrm{Na}+\mathrm{H}+$ exchanger 1 ubiquitylation, endocytosis, and function. J. Biol. Chem. 285, 38293-38303 (2010)

117. H. Rossmann, T. Sonnentag, A. Heinzmann, B. Seidler, O. Bachmann, D. Vieillard-Baron, M. Gregor, U. Seidler, Differential expression and regulation of $\mathrm{Na}(+) / \mathrm{H}(+)$ exchanger isoforms in rabbit parietal and mucous cells. Am. J. Physiol. Gastrointest. Liver Physiol. 281, G447-G458 (2001)

118. A.P.V. der Nolte, G. Chodisetti, Z. Yuan, F. Busch, B. Riederer, M. Luo, Y. Yu, M.B. Menon, A. Schneider, R. Stripecke, K. Nikolovska, S. Yeruva, U. Seidler, $\mathrm{Na}(+) / \mathrm{H}(+)$ exchanger NHE1 and NHE2 have opposite effects on migration velocity in rat gastric surface cells. J. Cell Physiol. 232, 1669-1680 (2017)

119. L. Xue, E. Aihara, T.C. Wang, M.H. Montrose, Trefoil factor 2 requires $\mathrm{Na} / \mathrm{H}$ exchanger 2 activity to enhance mouse gastric epithelial repair. J. Biol. Chem. 286, 38375-38382 (2011)

120. A.L. Matthis, I. Kaji, K.A. Engevik, Y. Akiba, J.D. Kaunitz, M.H. Montrose, E. Aihara, Deficient active transport activity in healing mucosa after mild gastric epithelial damage. Dig. Dis. Sci. 65, 119-131 (2020)

121. M. Czepán, Z. Rakonczay Jr., A. Varró, I. Steele, R. Dimaline, N. Lertkowit, J. Lonovics, A. Schnúr, G. Biczó, A. Geisz, G. Lázár, Z. Simonka, V. Venglovecz, T. Wittmann, P. Hegyi, NHE1 activity contributes to migration and is necessary for proliferation of human gastric myofibroblasts. Pflugers Arch. 463, 459-475 (2012)

122. R.A. Gatenby, K. Smallbone, P.K. Maini, F. Rose, J. Averill, R.B. Nagle, L. Worrall, R.J. Gillies, Cellular adaptations to hypoxia and acidosis during somatic evolution of breast cancer. Br. J. Cancer 97, 646-653 (2007)

123. H. Izumi, T. Torigoe, H. Ishiguchi, H. Uramoto, Y. Yoshida, M. Tanabe, T. Ise, T. Murakami, T. Yoshida, M. Nomoto, K. Kohno, Cellular $\mathrm{pH}$ regulators: Potentially promising molecular targets for cancer chemotherapy. Cancer Treat. Rev. 29, 541-549 (2003)

124. H.F. Liu, X.C. Teng, J.C. Zheng, G. Chen, X.W. Wang, Effect of NHE1 antisense gene transfection on the biological behavior of SGC-7901 human gastric carcinoma cells. World J. Gastroenterol. 14, 2162-2167 (2008)

125. S. Hosogi, H. Miyazaki, K. Nakajima, E. Ashihara, N. Niisato, K. Kusuzaki, Y. Marunaka, An inhibitor of $\mathrm{Na}(+) / \mathrm{H}(+)$ exchanger (NHE), ethyl-isopropyl amiloride (EIPA), diminishes proliferation of MKN28 human gastric cancer cells by decreasing the cytosolic $\mathrm{cl}(-)$ concentration via DIDS-sensitive pathways. Cell. Physiol. Biochem. 30, 1241-1253 (2012)

126. H. Nagata, X.F. Che, K. Miyazawa, A. Tomoda, M. Konishi, H. Ubukata, T. Tabuchi, Rapid decrease of intracellular $\mathrm{pH}$ associated with inhibition of $\mathrm{Na}+\mathrm{H}+$ exchanger precedes apoptotic events in the MNK45 and MNK74 gastric cancer cell lines treated with 2aminophenoxazine-3-one. Oncol. Rep. 25, 341-346 (2011)

127. B. He, M. Zhang, R. Zhu, Na+/H+ exchanger blockade inhibits the expression of vascular endothelial growth factor in SGC7901 cells. Onco.1 Rep. 23, 79-87 (2010)

128. M.G. Rosasco, S.E. Gordon, in Neurobiology of TRP Channels, ed. by T.L.R. Emir (CRC Press/Taylor \& Francis (c) 2018 by Taylor \& Francis Group, LLC., Boca Raton (FL), 2017), pp. 1-9

129. I.S. Ramsey, M. Delling, D.E. Clapham, An introduction to TRP channels. Annu. Rev. Physiol. 68, 619-647 (2006)

130. A. Fleig, R. Penner, The TRPM ion channel subfamily: Molecular, biophysical and functional features. Trends Pharmacol. Sci. 25, 633-639 (2004)
131. K. Nagamine, J. Kudoh, S. Minoshima, K. Kawasaki, S. Asakawa, F. Ito, N. Shimizu, Molecular cloning of a novel putative $\mathrm{Ca} 2+$ channel protein (TRPC7) highly expressed in brain. Genomics 54, 124-131 (1998)

132. R. Kraft, C. Harteneck, The mammalian melastatin-related transient receptor potential cation channels: An overview. Pflugers Arch. 451, 204-211 (2005)

133. Y. Huang, R. Fliegert, A.H. Guse, W. Lu, J. Du, A structural overview of the ion channels of the TRPM family. Cell Calcium 85, 102111 (2020)

134. S.A. Syed Mortadza, L. Wang, D. Li, L.H. Jiang, TRPM2 channel-mediated ROS-sensitive $\mathrm{Ca}(2+)$ signaling mechanisms in immune cells. Front. Immunol. 6, 407 (2015)

135. H. Knowles, J.W. Heizer, Y. Li, K. Chapman, C.A. Ogden, K. Andreasen, E. Shapland, G. Kucera, J. Mogan, J. Humann, L.L. Lenz, A.D. Morrison, A.L. Perraud, Transient receptor potential Melastatin 2 (TRPM2) ion channel is required for innate immunity against listeria monocytogenes. Proc. Natl. Acad. Sci. U. S. A. 108, 11578-11583 (2011)

136. S. Yamamoto, S. Shimizu, S. Kiyonaka, N. Takahashi, T. Wajima, Y. Hara, T. Negoro, T. Hiroi, Y. Kiuchi, T. Okada, S. Kaneko, I. Lange, A. Fleig, R. Penner, M. Nishi, H. Takeshima, Y. Mori, TRPM2-mediated Ca2+influx induces chemokine production in monocytes that aggravates inflammatory neutrophil infiltration. Nat. Med. 14, 738-747 (2008)

137. K. Uchida, K. Dezaki, B. Damdindorj, H. Inada, T. Shiuchi, Y. Mori, T. Yada, Y. Minokoshi, M. Tominaga, Lack of TRPM2 impaired insulin secretion and glucose metabolisms in mice. Diabetes 60, 119-126 (2011)

138. G.C. Jing, M.R. Zhang, Transient receptor potential melastatin 2: An ion channel for oxidative stress sensing. Zhongguo Yi Xue Ke Xue Yuan Xue Bao 38, 364-367 (2016)

139. C.H. Tan, P.A. McNaughton, The TRPM2 ion channel is required for sensitivity to warmth. Nature 536, 460-463 (2016)

140. K. Song, H. Wang, G.B. Kamm, J. Pohle, F.C. Reis, P. Heppenstall, H. Wende, J. Siemens, The TRPM2 channel is a hypothalamic heat sensor that limits fever and can drive hypothermia. Science 353, 1393-1398 (2016)

141. B.A. Miller, J.Y. Cheung, TRPM2 protects against tissue damage following oxidative stress and ischaemia-reperfusion. J. Physiol. 594, 4181-4191 (2016)

142. K.K. Wong, A.H. Banham, N.S. Yaacob, S.M. Nur Husna, The oncogenic roles of TRPM ion channels in cancer. J. Cell. Physiol. 234, 14556-14573 (2019). https://doi.org/10.1002/jcp. 28168

143. B.A. Miller, TRPM2 in cancer. Cell Calcium 80, 8-17 (2019)

144. S. Almasi, B.E. Kennedy, M. El-Aghil, A.M. Sterea, S. Gujar, S. Partida-Sanchez, Y. El Hiani, TRPM2 channel-mediated regulation of autophagy maintains mitochondrial function and promotes gastric cancer cell survival via the JNK-signaling pathway. J. Biol. Chem. 293, 3637-3650 (2018)

145. S. Almasi, A.M. Sterea, W. Fernando, D.R. Clements, P. Marcato, D.W. Hoskin, S. Gujar, Y. El Hiani, TRPM2 ion channel promotes gastric cancer migration, invasion and tumor growth through the AKT signaling pathway. Sci. Rep. 9, 4182 (2019)

Publisher's note Springer Nature remains neutral with regard to jurisdictional claims in published maps and institutional affiliations. 